\title{
TORQUE RIPPLES MINIMIZATION ON DTC CONTROLLED INDUCTION MOTOR WITH ADAPTIVE BANDWIDTH APPROACH
}

\author{
Fatih Korkmaz ${ }^{1}$, Yilmaz Korkmaz $^{2}$,İsmail Topaloğlu ${ }^{1}$ and Hayati Mamur ${ }^{1}$ \\ ${ }^{1}$ Department of Electric and Electronic Engineering, \\ Çankırı Karatekin University, Çankırı, Turkey \\ fkorkmaz@karatekin.edu.tr \\ ${ }^{2}$ Faculty of Technology, \\ Department of Electric and Electronic Engineering, \\ Gazi University, Ankara, Turkey
}

\begin{abstract}
Field oriented control (FOC) and direct torque control (DTC), also called vector control, are most famous control methods in high-performance motor applications. If we want to specify the basic handicaps of both methods: the FOC has parameter dependence while the DTC has high torque ripples. This paper proposes a new adaptive bandwidth approach to reduce torque ripples in DTC controlled induction motor drives. With the proposed method, instead of fixed bandwidth, adaptive bandwidth approach is investigated in hysteresis controllers on the DTC method. Both the conventional DTC $(C-D T C)$ method and adaptive bandwidth DTC (AB-DTC) for induction motor are simulated in MATLAB/SIMULINK and the results are presented and discussed to verify the proposed control. The comparisons have shown that, torque ripples have been reduced remarkably with the proposed $A B$-DTC method.
\end{abstract}

\section{KEYWORDS}

Direct torque control, Adaptive hystresis controller, Induction motor control, Vector control

\section{INTRODUCTION}

Three-phase induction motors (IMs) are the most common motors used in industrial control systems and commercial applications. Simple and rugged design, low-cost, low maintenance and direct connection to an AC power source are the main advantages of IMs[1].

In the past, IMs were preferred only constant speed applications because of speed adjustment on IMs were not only hard to realize but also need high costs. So, DC motors were the optimum option for the variable speed applications. But over the years, this situation has changed depending on developments in power electronics and semiconductor technology. As a result, many kinds of IM variable speed driver have been produced and now the IMs are very good alternative for variable speed applications.

Today, vector controlled drivers are the most popular variable speed driver for the IMs and vector control methods can basically be grouped under two headings: FOC and DTC. The FOC was first introduced by Blaschke [2] in the 1970's. It was unrivalled in industrial induction motor drivers until DTC was introduced by Takahashi [3] in the middle of the 1980's. It was a good alternative Jan Zizka et al. (Eds) : DBDM, CICS, CCNET, CSIP - 2015 
to FOC due to some well-known advantages, such as simple control structure, no need much motor parameters so independency of parameter changes, fast dynamic response. Besides these advantages, DTC scheme still had some disadvantages like high torque and current ripples, variable switching frequency behaviour and implementation difficulties owing to necessity of low sampling time [4].

Despite, the DTC was originally developed for induction motor drives, it has also been applied other motor types like PMSM and BLDC [5-6]. When we look at the recent studies about the DTC, we can see that many kinds of approaches have been investigated to overcome the high torque and current ripple problems on DTC method.

In these studies, researchers proposed different ways. Some studies suggest using different switching techniques and inverter topologies [7-8], in another group of researchers, different observer models have been suggested [9-10]. On the other hand, intelligent control methods like fuzzy logic have been explored by several researchers for its potential to improve the speed regulation of the drive system. [11-12]

In this paper, a new hysteresis controller algorithm is presented to improve the dynamic torque performance of the DTC controlled IM. To illustrate the effect of the proposed system, conventional and proposed systems are simulated in Matlab/Simulink environment and results have been analyzed. Simulation studies have proved that this method reduces the torque ripple of the DTC method.

\section{BASICS OF DTC}

Direct torque control (DTC) directly controls the flux linkage and electromagnetic torque, considering the motor, voltage source inverter, and the control strategy at the system level. A relationship is established between the torque, the flux and the optimal inverter switching so as to achieve a fast torque response. It exhibits better dynamic performance than conventional control methods, such as vector control, is less sensitive to parameter variations, and is simpler to implement [13].

The DTC bases on the selection of the optimum voltage vector which makes the flux vector rotate and produce the demanded torque. In this rotation, the amplitude of the flux and the torque errors are kept within acceptable limits by hysteresis controllers [14]. The rotation of the stator flux vector and an example of the effects of the applied inverter switching vectors are given in the Fig.

1. The DTC allows for very fast torque responses, and flexible control of the induction motor. The flux and torque errors are kept within acceptable limits by hysteresis controllers [15].
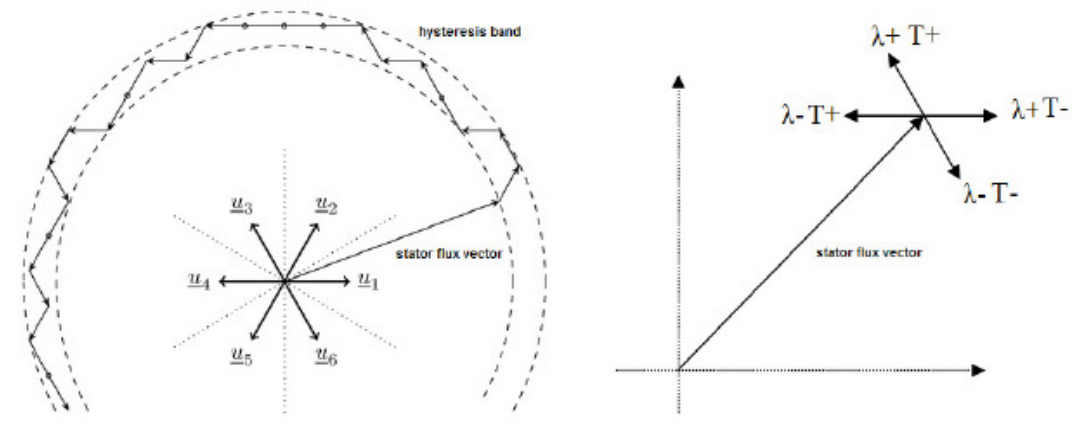

Figure 1. The rotation of the stator flux vector and an example for the effects of the applied inverter switching vectors [16]. 
The block diagram of the conventional DTC controlled motor is given in Fig. 2.

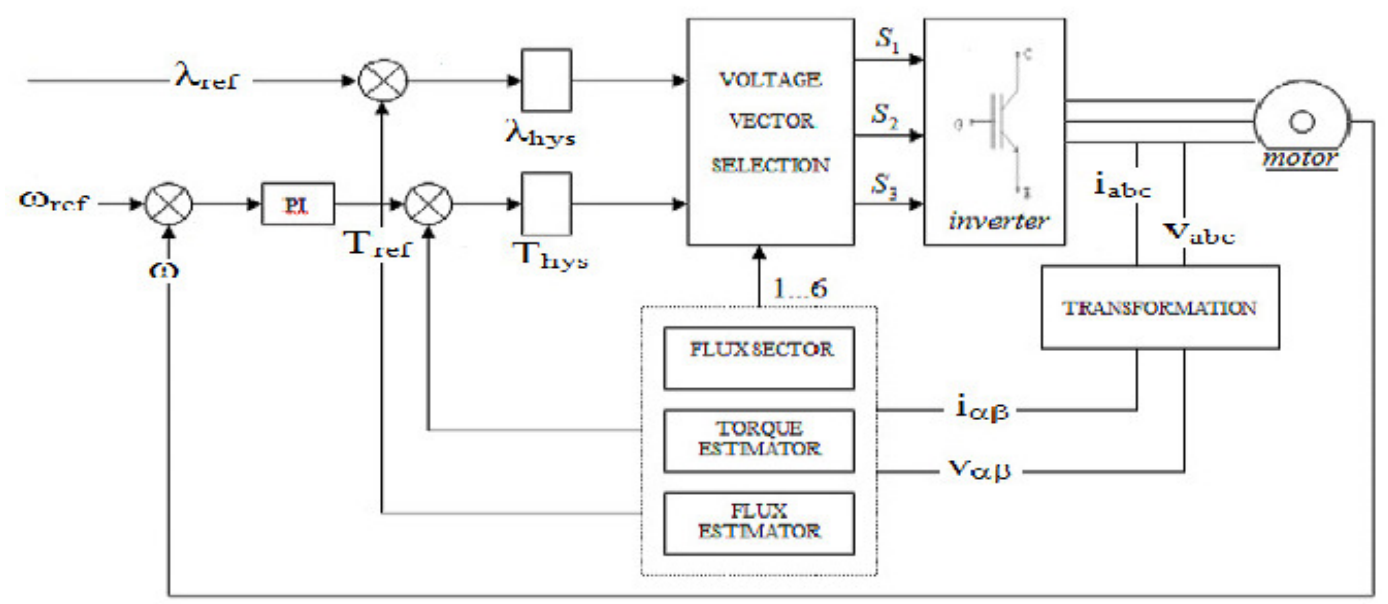

Figure 2. The block diagram of the conventional DTC

The DTC algorithm controls the stator flux and the torque by using measured currents and voltages.

The instantaneous values of the flux and torque can be obtained by using the transformation of the measured currents and the voltages of the motor. The stator flux is calculated as given in Eq.1-3 in a stationary reference frame.

$$
\begin{aligned}
& \lambda_{\alpha}=\int\left(V_{\alpha}-R_{s} i_{\alpha}\right) d t \\
& \lambda_{\beta}=\int\left(V_{\beta}-R_{s} i_{\beta}\right) d t \\
& \lambda=\sqrt{\lambda_{\alpha}^{2}+\lambda_{\beta}^{2}}
\end{aligned}
$$

Where, $\lambda_{\alpha}-\lambda_{\beta}$ are stator fluxes, $i_{\alpha}-i_{\beta}$ are stator currents, $V_{\alpha}-V_{\beta}$ are stator voltages, $\alpha-\beta$ components and $R_{s}$ is the stator resistance. Motor torque can be calculated as given in Eq.4.

$$
T_{e}=\frac{3}{2} p\left(\lambda_{\alpha} i_{\beta}-\lambda_{\beta} i_{\alpha}\right)
$$

Where, $p$ is the motor pole pairs. The stator flux vector region is an important parameter for the DTC, and it can be calculated as given in Eq.5:

$\theta_{\lambda}=\tan ^{-1}\left(\frac{\lambda_{\beta}}{\lambda_{\alpha}}\right)$

The torque and flux errors, which are obtained by comparing the reference and observed values, are converted to control signals by hysteresis comparators. The switching table is used to determine the optimum switching inverter states, and it determines the states by using the hysteresis comparator outputs and the flux region data [17]. 


\section{ADAPTIVE BANDWIDTH APPROACH}

Hysteresis control is one of PWM methods used for generating pulses to order the power switches of the inverter. Among the various current control techniques, it is widely used due to the fast response, simple implementation, negligible tracking error, inherent robustness to load parameter variations and proper stability [18].

In DTC method, two different hysteresis controllers are used to determine the changes in stator flux and electromagnetic torque. In constant bandwidth approach, small bandwidth values results in a higher switching frequency. So, it results in low harmonic copper losses in the motor while switching losses in the inverter are high. Conversely, in a large bandwidth values case, switching losses decrease in the inverter while the harmonic copper losses increase in the motor [19]. So selection of optimum amplitude of flux and torque hysteresis band is important for the drive but there are no certainties to determine optimum amplitude of hysteresis bandwidth.

The main idea of adaptive hysteresis bandwidth approach as given in Fig. 3.

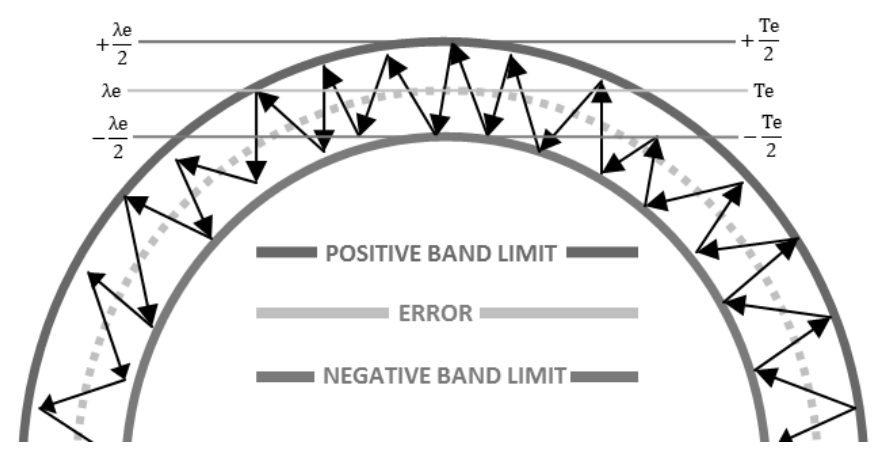

Figure 3. Adaptive hysteresis bandwidth

In this approach hysteresis bandwidth is determined by error values in the previous step for stator flux and electromagnetic torque. So, for the next step of the control process, hysteresis bandwidth is adapted with change in error. It means, if error on flux / torque is high, hysteresis bandwidth will be extended, on the contrary, if error on flux / torque is low, hysteresis bandwidth will be reduced. In this way, hysteresis bandwidth is designed to be flexible and the control algorithm tries to minimize previous step errors at every step. In other words, flux and torque errors are associated with each other with this approach.

\section{SIMULATIONS AND RESULTS}

The C-DTC and the proposed AB-DTC drive systems have been developed using Matlab/Simulink and the AB-DTC system with the Simulink blocks is shown in Fig. 4. 


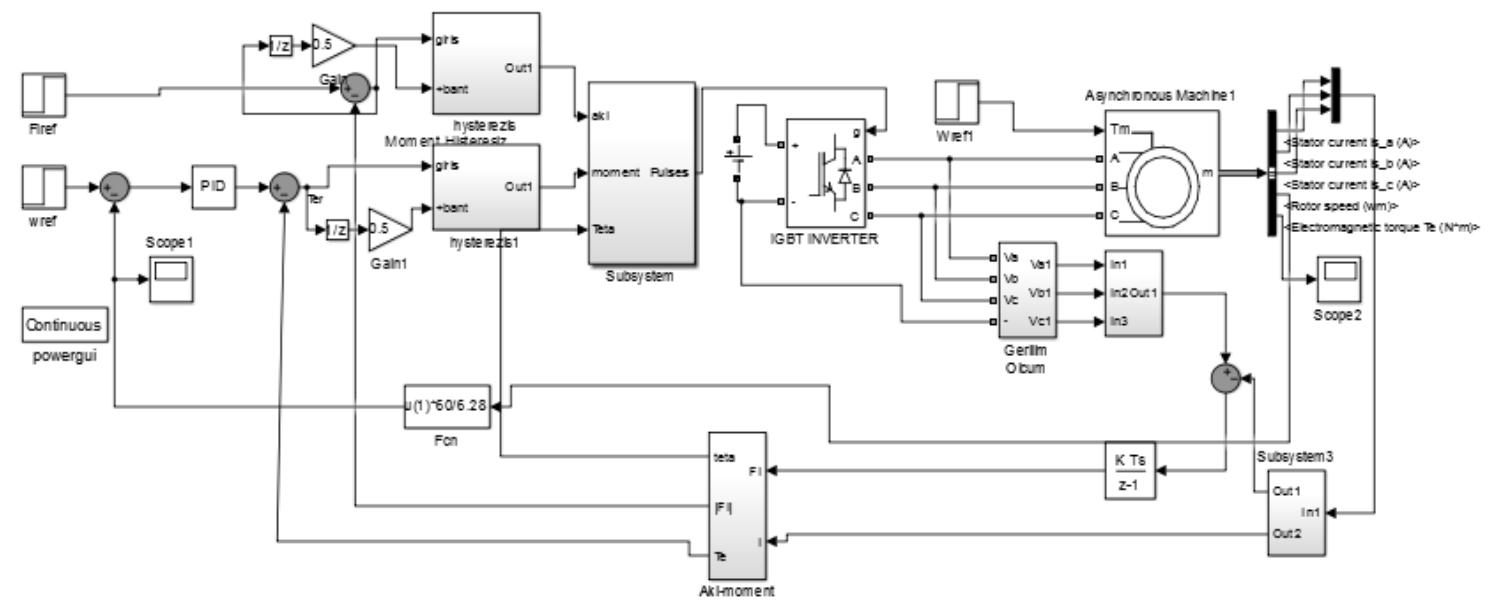

Figure 4. The proposed AB-DTC system with the Simulink blocks

The both control systems have been simulated in order to demonstrate the validity of the proposed AB-DTC system. The sampling interval is $50 \mu$ s. The magnitudes of the torque and flux hysteresis bands in the C-DTC are $0.1 \mathrm{Nm}$ and $0.02 \mathrm{~Wb}$, respectively. The nominal motor parameters are mentioned in Table.

Table. Specifications and parameters of the IM

\begin{tabular}{|c|c|c|}
\hline Symbol & Quantity & Value \\
\hline $\mathrm{P}$ & Power $(\mathrm{kW})$ & 1.1 \\
\hline $\mathrm{V}_{\mathrm{n}}$ & Line to Line voltage $(\mathrm{V})$ & 230 \\
\hline $\mathrm{p}$ & Number of poles & 2 \\
\hline $\mathrm{f}$ & Frequency $(\mathrm{Hz})$ & 50 \\
\hline $\mathrm{R}_{\mathrm{s}}$ & Stator resistance $(\Omega)$ & 8 \\
\hline $\mathrm{Lm}$ & Mutual inductance $(\mathrm{H})$ & 0.55 \\
\hline $\mathrm{L}$ & Inductance $(\mathrm{H})$ & 0.018 \\
\hline
\end{tabular}

To investigate and compare the performances of the C-DTC and the AB-DTC algorithms, unloaded and rated loaded $(3 \mathrm{Nm}$ ) working conditions are employed. The speed reference is set at $2800 \mathrm{rpm}$ for both conditions. The electromagnetic torque responses of motor for unloaded and loaded conditions are shown in Fig. 5 and Fig. 6., respectively.

As it can be seen if Fig. 5, for unloaded working conditions, the C-DTC torque ripple changes in $\pm 1.5 \mathrm{Nm}$ band while the AB-DTC changes in $\pm 1 \mathrm{Nm}$. It means the motor torque ripple has been reduced about $65 \%$ with the proposed DTC method for unloaded working conditions. 

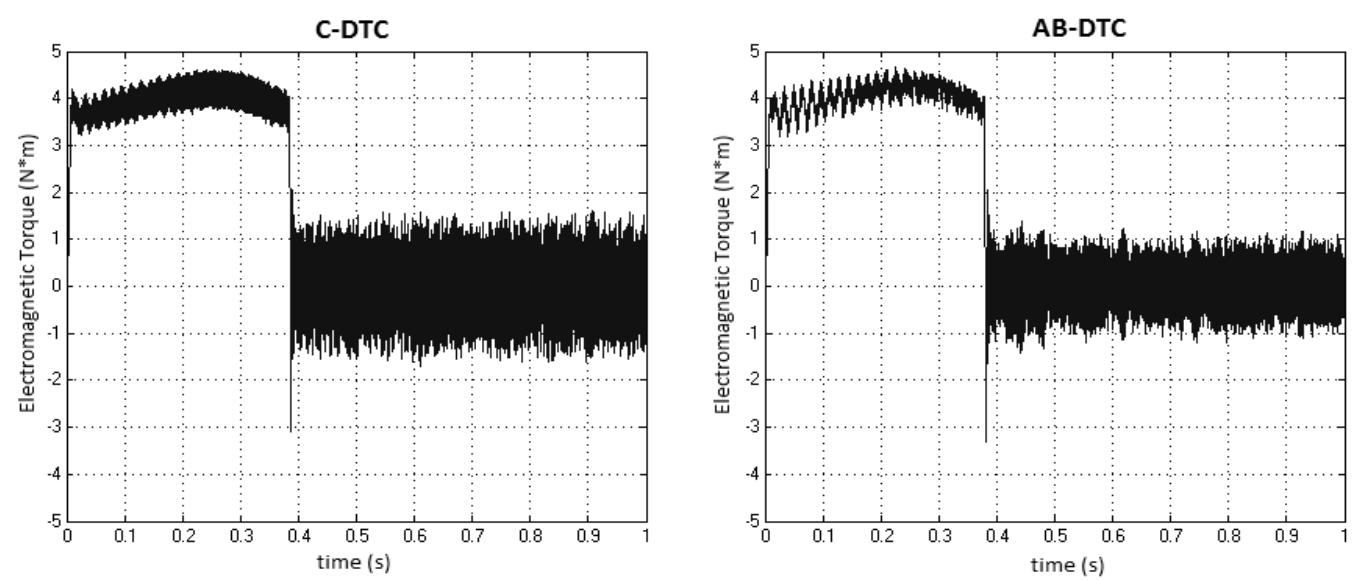

Figure 5. Electromagnetic torque responses at unloaded working conditions
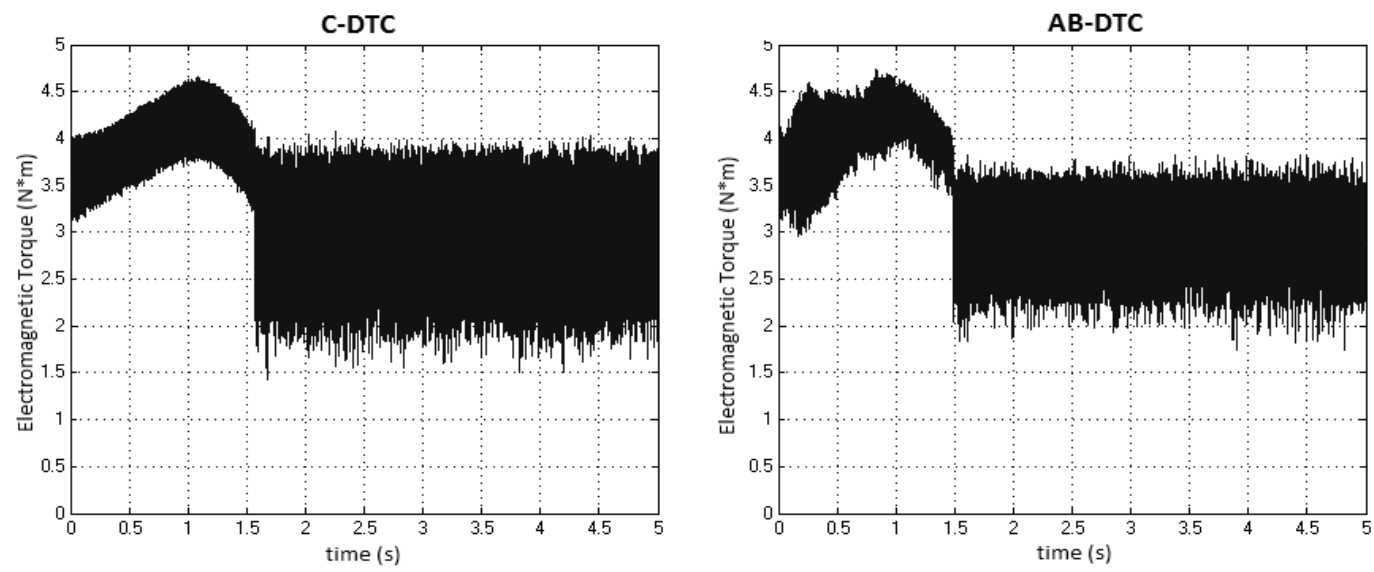

Figure 6. Electromagnetic torque responses at loaded working conditions

If we investigate loaded working conditions, as it can be seen in Fig. 6, the C-DTC torque ripple band changes between about $4 \mathrm{Nm} / 1.75 \mathrm{Nm}$ (bandwidth $2.25 \mathrm{Nm}$ ) and the AB-DTC torque ripple band changes between about $3.6 \mathrm{Nm} / 2.25 \mathrm{Nm}$ (bandwidth $1.35 \mathrm{Nm}$ ). It means the motor torque ripple has been reduced about $60 \%$ with the proposed DTC method for loaded working conditions. So, in general, it must be pointed out that the torque ripple of the motor has been reduced about $60 \%$ with the proposed DTC approach.

\section{CONCLUSIONS}

The conventional DTC offers several inherent advantages such as faster dynamic performance and robust controller structure compared to the Field Oriented Control for IMs. However, most faced problem in the C-DTC is high torque ripple. This paper presents an adaptive control algorithm on hysteresis controllers which are directly effect on system performance. In this approach hysteresis controller band limits are not constant and band limits are determined by error values in the previous step for stator flux and electromagnetic torque. The proposed approach is verified by the Matlab simulation and the obtained results shows that the proposed DTC approach can significantly reduce the torque ripple and improve the drive performance. 


\section{REFERENCES}

[1] Rakesh Parekh, (2003) “AC Induction Motor Fundamentals”, Microchip Technology Inc, AN887, DS00887A, pp 1-24.

[2] Blaschke, F.,(1972) "The Principle of Field Orientation Applied to The New Transvector ClosedLoop Control System for Rotating Field Machines”, Siemens-Rev., Vol. 39, 217-220.

[3] Takahashi, I. \& Noguchi. T. (1986) "A new quick-response and high efficiency control strategy of an induction motor,” IEEE Transactions on Industrial Applications, vol.I A-22 ,No.5. , pp. 820-827.

[4] Fatih Korkmaz. \& M. Faruk Çakır. \& Yılmaz Korkmaz. \& Ismail Topaloglu, (2012) "Fuzzy Based Stator Flux Optimizer Design For Direct Torque Control” International Journal of Instrumentation and Control Systems (IJICS) Vol.2, No.4, pp 41-49.

[5] Fatih Korkmaz. \& M.Faruk Cakır. \& İsmail Topaloğlu. \& Rıza Gurbuz, (2013) “Artificial Neural Network Based DTC Driver for PMSM", International Journal of Instrumentation and Control Systems (IJICS) Vol.3, No.1, pp 1-7.

[6] Masmoudi, M. \& El Badsi, B. \& Masmoudi, A.,(2014) "Direct Torque Control of Brushless DC Motor Drives With Improved Reliability," Industry Applications, IEEE Transactions on , vol.50, no.6, pp.3744,3753. doi: 10.1109/TIA.2014.2313700

[7] D. Casadei. \& G. Serra. \& A. Tani,(2001) "The use of matrix converters in direct torque control of induction machines", IEEE Trans. on Industrial Electronics, vol.48 , no.6 , pp. 1057-1064.

[8] D. Casadei. \& G. Serra. \& A. Tani,(2000) "Implentation of a direct torque control algorithm for induction motors based on discrete space vector modulation", IEEE Trans. on Power Electronics, vol. 15 , no. 4 , pp. $769-777$.

[9] Z. Tan. \& Y. Li . \& Y. Zeng,(2002) “A three-level speed sensorless DTC drive of induction motor based on a full-order flux observer", Power System Technology, Proceedings. PowerCon International Conference, vol. 2, pp. 1054- 1058.

[10] G. Yav. \& L. Weiguo, (2011) "A new method research of fuzzy DTC based on full-order state observer forstator flux linkage”, Computer Science and Automation Engineering (CSAE), 2011 IEEE International Conference, vol. 2 , pp.104-108.

[11] S. Benaicha. \& F. Zidani. \& R.-N. Said. \& M.-S.-N. Said,(2009) "Direct torque with fuzzy logic torque ripple reduction based stator flux vector control", Computer and Electrical Engineering, (ICCEE '09), vol.2, pp. 128-133.

[12] N. Sadati. \& S. Kaboli. \& H. Adeli. \& E. Hajipour \& \& M. Ferdowsi,(2009) "Online optimal neurofuzzy flux controller for dtc based induction motor drives”, Applied Power Electronics Conference and Exposition (APEC 2009), pp.210-215.

[13] Liu, Y. \& Zhu, Z.Q. \& Howe, D. (2005) "Direct torque control of brushles DC drives with reduced torque ripple”, IEEE Transactions on Industry Applications, 41(2). pp 599-608.

[14] P. Vas,(2003) “Sensorless vector and direct torque control”, Oxford University Press.

[15] Kaboli, S. \& Zolghadri, M.R. \& Haghbin, S. \& Emadi, A.,(2003) "Torque ripple minimization in DTC of induction motor based on optimized flux value determination", IEEE Ind. Electron. Conf., pp. 431-435. 
[16] Fatih Korkmaz. \& Ismail Topaloglu. \& Hayati Mamur (2013) "Fuzzy Logic Based Direct Torque Control Of Induction Motor with Space Vector Modulation", International Journal on Soft Computing, Artificial Intelligence and Applications (IJSCAI), Vol.2, No. 5/6, pp 31-40.

[17] Yilmaz Korkmaz. \& Fatih Korkmaz. \& Ismail Topaloglu . \& Hayati Mamur, (2014) "Comparing of Switching Frequency on Vector Controlled Asynchronous Motor", International Journal on Soft Computing, Artificial Intelligence and Applications (IJSCAI), Vol.3, No. 3/4, pp 19-27.

[18] Seyed Mehdi Abedi. \& Hani Vahedi, (2013) "Simplified Calculation of Adaptive Hysteresis Current Control to be Used in Active Power Filter", Trends in Applied Sciences Research, 8(1), pp 46-54.

[19] H. Ibrahim OKUMUS. \&Mustafa AKTAS,(2010) "Adaptive hysteresis band control for constant switching frequency in DTC induction machine drives”, Turk J Elec Eng \& Comp Sci, Vol.18, No.1, pp 59-69. 